\title{
Generalised muscular weakness after botulinum toxin injections for dystonia: a report of three cases
}

\author{
K P Bhatia, A Münchau, P D Thompson, M Houser, V S Chauhan, M Hutchinson, \\ A H V Shapira, C D Marsden*
}

Department of Clinical Neurology, Institute of

Neurology, University College, London, Queen Square,

London, UK

K P Bhatia

A Münchau

P D Thompson

$M$ Houser

V S Chauhan

A H V Shapira

C D Marsden*

St Vincents Hospital, Elm Park, Dublin,

Ireland

M Hutchinson

University

Department of Clinical

Neurosciences, Royal

Free and UCH Medical

Sciences, University

College London,

London

A H V Shapira

*Deceased 29 September 1998

Correspondence to: Dr KP Bhatia, Institute of Neurology, Queen Square, London WC1N 3BG, UK. Telephone 0044171837

3611; fax 0044171278

5616.

Received 22 September 1998 and in revised form

11 December 1998

Accepted 22 December 1998

\begin{abstract}
Three patients are reported on who developed transient generalised weakness after receiving therapeutic doses of botulinum toxin for cervical dystonia (one case) and symptomatic hemidystonia (two cases) respectively. Clinical and electrophysiological findings were in keeping with mild botulism. All patients had received previous botulinum toxin injections without side effects and one patient continued injections without recurrence of generalised weakness. The cause is most likely presynaptic inhibition due to systemic spread of the toxin. Patients with symptomatic dystonia may be more likely to have this side effect and botulinum toxin injections in these patients should be carried out cautiously.
\end{abstract}

(F Neurol Neurosurg Psychiatry 1999;67:90-93)

Keywords: botulism; botulinum toxin injections; dystonia

Botulinum toxin injections are effective in focal dystonias and other conditions including spasticity. Therapy with botulinum toxin is relatively safe with few side effects, mostly related to local diffusion into adjacent areas-for example, dysphagia after injections for torticollis. ${ }^{1}$ Systemic effects are few and may be immune mediated-for instance, anaphylaxis and flu-like symptoms. Recently, brachial neu- ritis has been described after botulinum toxin injections for writer's cramp and may also be immune mediated. ${ }^{2}$

Botulinum toxin prevents acetylcholine release presynaptically at the neuromuscular junction and a dose dependent degree of chemodenervation develops in the injected muscle. Subclinical effects of botulinum toxin on neuromuscular transmission distant from the site of injection have been reported, as shown by increase in jitter, increased fibre density, and occasional blocks on single fibre EMG ${ }^{3-7}$ However, apart for one recent report, ${ }^{8}$ clinically detectable generalised weakness with concurrent EMG changes has not been described in patients receiving botulinum toxin injections for focal dystonia. We report on three patients in whom treatment of their dystonia with therapeutic doses of botulinum toxin resulted in generalised weakness (table).

\section{Case summaries}

CASE 1

This 45 year old woman presented with cervical dystonia in October 1988. A year later dystonia spread to involve the face and speech. She also developed a jerky "no-no" head tremor. There was no family history of dystonia but there was a family history of autoimmune disorders. Her great uncle had pernicious anaemia, two aunts had vitiligo, and a cousin had rheumatoid arthritis.

Table Summary of clinical and electrophysiological features of reported patients with generalised weakness after BT injections

\begin{tabular}{|c|c|c|c|c|c|c|c|}
\hline Age/ sex & $\begin{array}{l}\text { Injections for } \\
\text { (primary } \\
\text { diagnosis) }\end{array}$ & $\begin{array}{l}\text { Prior years of } \\
\text { injections }\end{array}$ & $\begin{array}{l}\text { Muscles injected } \\
\text { /total dose }\end{array}$ & $\begin{array}{l}\text { Distribution of } \\
\text { weakness }\end{array}$ & $\begin{array}{l}\text { Onset } \\
\text { /duration }\end{array}$ & Electrophysiology & $F U$ \\
\hline \multicolumn{8}{|c|}{ Our patients: } \\
\hline $45 / \mathrm{F}$ & Cervical dystonia & 5 & $\begin{array}{l}\text { scm, splenii, } \\
/ 650 \text { U/Dys }\end{array}$ & $\begin{array}{l}\text { Generalised UL>LL } \\
\text { dysphagia }\end{array}$ & $\begin{array}{l}1 \text { week } \\
/ 6 \text { months }\end{array}$ & $\begin{array}{l}\text { Fibrillations, small and short MUP } \\
\text { abnormal jitter, and blockings } \\
\text { Mild decrement }\end{array}$ & $\begin{array}{l}\text { Recovered, no further } \\
\text { injections }\end{array}$ \\
\hline $57 / \mathrm{F}$ & $\begin{array}{l}\text { Arm dystonia } \\
\text { (symptomatic } \\
\text { hemidystonia) }\end{array}$ & 2.5 & $\begin{array}{l}\mathrm{L} \text { arm } \\
/ 900 \mathrm{U} / \mathrm{Dys}\end{array}$ & Generalised UL>LL & $\begin{array}{l}2 \text { weeks } \\
13 \text { months }\end{array}$ & $\begin{array}{l}\text { Abnormal jitter and blocking } \\
\text { Mild decrement }\end{array}$ & $\begin{array}{l}\text { Recovered, no } \\
\text { problems with further } \\
\text { injections }\end{array}$ \\
\hline $32 / \mathrm{F}$ & $\begin{array}{l}\text { Leg dystonia } \\
\text { (symptomatic } \\
\text { hemidystonia) }\end{array}$ & 2.5 & $\begin{array}{l}\text { L foot } \\
/ 600 / \text { Dys }\end{array}$ & $\begin{array}{l}\text { Generalised UL>LL } \\
\text { dysphagia }\end{array}$ & $\begin{array}{l}1 \text { week } \\
13 \text { months }\end{array}$ & $\begin{array}{l}\text { EMG normal } \\
\text { SFEMG normal }\end{array}$ & $\begin{array}{l}\text { Similar episode on } \\
\text { repeat injections. None } \\
\text { since }\end{array}$ \\
\hline \multicolumn{8}{|c|}{ Reported cases (Bakheit $e t a l^{8}$ ) } \\
\hline $67 / \mathrm{F}$ & Spasticity (MS) & $\begin{array}{l}\text { nil } \\
1 \times \text { injection }\end{array}$ & $\begin{array}{l}\text { L leg } \\
/ 250 \mathrm{U} / \mathrm{Dys}\end{array}$ & $\begin{array}{l}\text { Generalised LL>UL } \\
\text { dysphagia ptosis }\end{array}$ & $\begin{array}{l}4 \text { days } \\
/ 4 \text { weeks }\end{array}$ & $\begin{array}{l}\text { EMG "denervation" } \\
\text { Abnormal jitter and blocking }\end{array}$ & Recovered \\
\hline $34 / \mathrm{F}$ & $\begin{array}{l}\text { Torticollis } \\
\text { (MSA) }\end{array}$ & 5 & $\begin{array}{l}\text { scm, splenius } \\
\text { /250 U/Dys }\end{array}$ & $\begin{array}{l}\text { Generalised proximal } \\
\text { dysphagia }\end{array}$ & $\begin{array}{l}3 \text { weeks } \\
14 \text { months }\end{array}$ & $\begin{array}{l}\text { EMG "denervation" } \\
\text { Abnormal jitter and blocking }\end{array}$ & Recovered \\
\hline
\end{tabular}

$\mathrm{Scm}=$ sternocleidomastoid muscle; $\mathrm{LL}=$ lower limb; UL=upper limbs; Dys=Dysport, RNS=repetitive nerve stimulation; $\mathrm{SFEMG=single} \mathrm{fibre} \mathrm{EMG}$; $\mathrm{MUP}=\mathrm{motor}$ unit potentials; $\mathrm{MSA}=$ muscle system atrophy; $\mathrm{MS}=$ =multiple sclerosis. 
In November 1989 botulinum toxin A (Dysport) injections were started. Since 1993 she was receiving $650 \mathrm{U}$ Dysport in her neck muscles (150 $\mathrm{U}$ in the right sternocleidomastoid, $300 \mathrm{U}$ in the left splenius capitus, and $200 \mathrm{U}$ in the right splenius capitus muscle) at intervals of 12-14 weeks without side effects apart from occasional mild dysphagia which wore off over about 2 weeks.

In late 1995 she developed, for the first time, generalised fatigue and limb weakness within 1-2 weeks after the latest set of injections; these symptoms lasted 2-4 weeks. She did not have diplopia, dysphagia, ptosis, or altered speech and there was no diurnal variation of her symptoms. After injections in May 1996 (same dose and same sites) she had developed proximal weakness of the arms with swallowing difficulty and nasal regurgitation. On examination a week after her last injections she had mild wasting of the trapezius and spinati bilaterally without fasciculations. There was moderately severe weakness of the deltoids and spinati bilaterally, the biceps and triceps asymmetrically (left weaker than right), and the wrist and finger extensors (bilaterally). The rest of the examination was normal. An edrophonium (Tensilon) test was equivocal.

Apart from an increased creatine kinase concentration (659 IU/1), routine blood tests gave normal results. Rheumatoid factor and an autoimmune antibody screen including acetylcholine receptor antibodies and antibotulinum toxin antibodies were negative.

The first electrophysiological study was done 2 weeks after her last botulinum toxin injections. Routine nerve conduction studies were normal. After percutaneous supramaximal repetitive nerve stimulation at $3 \mathrm{~Hz}$ of right median nerve at the wrist maximal decrement of compound muscle action potential (CMAP) of the abductor pollicis brevis was $10 \%$. There was no decrement after stimulation of the right ulnar nerve. Routine needle EMG of the right deltoid, extensor digitorum communis, vastus lateralis, and tibialis anterior muscles showed occasional fibrillation potentials. Motor unit potentials were of low amplitude and brief duration and the number of polyphasic motor unit potentials was increased.

In a single fibre EMG study, 10 potential pairs were examined in the extensor digitorum communis. Five pairs had increased jitter (mean of $93.6 \mu \mathrm{s}$ ). Blockings were found in four pairs. These findings were in keeping with a disturbance of neuromuscular transmission.

Left triceps muscle biopsy in August 1996 showed changes consistent with muscle denervation.

As the patient's clinical state improved, a second EMG/single fibre EMG study was carried out 4 months after her last botulinum toxin injections. Routine EMG of the right deltoid, extensor digitorum communis, and iliopsoas showed changes similar to the previous study. On single fibre EMG 10 potential pairs were examined in each of these muscles, with eight, nine, and eight pairs showing excessive jitter respectively. There were frequent blockings only in the iliopsoas.
Nine months after the patient's last botulinum toxin injections when her generalised weakness had entirely resolved, motor nerve conduction studies of right median and ulnar nerve were normal. After repetitive nerve stimulation of the right median nerve maximal decrement of CMAP of the abductor pollicis brevis was $14 \%$ before and $12 \%$ after exercise. Decrement was $9 \%$ in the right deltoid after repetitive nerve stimulation of the axillary nerve both before and after exercise. Repetitive nerve stimulation of the ulnar was normal. single fibre EMG of the right extensor digitorum communis showed no blockings in 15 potential pairs that were examined. Mean jitter was normal $(20.1 \mu \mathrm{s})$.

The patient has not had botulinum toxin injections since May 1996; clinically she has normal muscle strength and normal swallowing, but her dystonia has worsened.

CASE 2

A 57 year old woman presented with a lifelong history of a non-progressive left hemidystonia due to a right lentiform nucleus vascular lesion evident on brain CT. Her left forearm was flexed at the elbow and pronated. Fingers of the hand were extended and the left thumb adducted and opposed across the palm. In March 1989200 U botulinum toxin A were injected into the left brachioradialis and left biceps with good results. One month later additional injections were given into the left adductor pollicis brevis and opponens pollicis muscles (40 U each). Over the subsequent 30 months she received eight further sets of injections (total dose at each visit ranged from 350$800 \mathrm{U}$ ) into these muscles at intervals of $10-12$ weeks; the dystonic spasms were improved and there were no side effects.

In October 1991300 U Dysport was administered into each of the following muscles; left biceps, left brachioradialis, left flexor carpi ulnaris, and $100 \mathrm{U}$ into the left adductor pollicis (total dose $900 \mathrm{U}$ ). Fourteen days later she felt generally unwell, complained of exertional fatigue on walking short distances or climbing staircases, and could not carry grocery bags. There was no diurnal fluctuation and she had no diplopia or swallowing difficulty. The symptoms lasted 1 month and slowly began to resolve.

When examined in December 1991, there was weakness of the right deltoid, right finger extensors, and left knee flexors.

Routine motor and sensory nerve conduction studies were normal. Repetitive nerve stimulation of the right median nerve showed a maximal decrement of CMAP of the abductor pollicis brevis of $12 \%$. Maximal decrement after 15 seconds of exercise was $9 \%$. repetitive nerve stimulation of ulnar, musculocutaneous, and accessory nerve was normal. Routine EMG of the right extensor digitorum communis, biceps, and triceps was normal. Single fibre EMG was performed in the right extensor digitorum communis and right biceps muscles. In the extensor digitorum communis, 11 pairs were studied and three of these showed abnormal jitter without blockings. Single fibre EMG of biceps was normal. The findings were 
suggestive of a disorder of neuromuscular transmission.

One month later clinical examination was normal. In February 1992 maximal decrement after repetitive nerve stimulation of both the median and ulnar nerve was normal $(<10 \%)$. There was no increment after prolonged exercise. She has since received a further six sets of botulinum toxin injections not exceeding 600 $\mathrm{U}$ on each occasion without side effects.

CASE 3

A 32 year old woman presented in 1985 with a 4 year history of a non-progressive posttraumatic hemidystonia after a closed head injury with transient left hemiparesis at age 17 . She complained of spasms of flexion of the toes and a tendency to plantarflexion of the left foot. Since January 1988 she had received injections of botulinum toxin $\mathrm{A}$ into the left flexor hallucis brevis, flexor digitorium brevis, and at times, into the soleus and flexor digitorum longus muscles. Injections were made at 8 to 10 week intervals with an average of $600 \mathrm{U}$ botulinum toxin at each visit.

After the eighth set of injections in May 1990 she reported increasing weakness of her arms and difficulty washing and combing her hair. She also noted difficulty getting out of the bath, slight drooping of her left eyelid, slurring of speech, and difficulty swallowing towards the end of a meal. On examination there was moderate weakness of shoulder abduction, elbow extension, and of the long finger extensors bilaterally. An edrophonium (Tensilon) test showed improved muscle strength but caused diplopia. Tests for acetylcholine receptor antibodies were negative. She was given pyridostigmine (240 mg daily) in divided doses, which produced some improvement in strength. Over the next 3 months she recovered fully. In October 1990 in addition to the usual injections, a further dose of $200 \mathrm{U}$ was given into the left gastrocnemius for worsening painful left foot dystonia. Ten days later the previous muscle weakness returned. Single fibre EMG in December 1990 showed normal jitter without blocking. Eventual full recovery occurred over the next 2 months.

\section{Discussion}

The three patients described here have similarities (table).

All had been receiving repeated botulinum toxin injections in therapeutic dosages for some years for their focal or segmental dystonia but then developed clinical muscle weakness distant from the site of injections. The weakness was temporally related to the injections and disappeared gradually over the subsequent 8 weeks in two patients and over 4 months in one patient. These patients were all negative for acetylcholine receptor antibodies and were not taking drugs known to impair neuromuscular transmission.

The clinical course in all patients and electrophysiological findings in two patients (spontaneous activity and small motor unit potentials of short duration on EMG in one patient, increased jitter and blockings on single fibre EMG in two patients, and borderline decrement after low frequency repetive nerve stimulation in two patients) were suggestive of a disorder of neuromuscular junction reminiscent of botulism in which spontaneous activity is often found. ${ }^{9}$ Classically, CMAP amplitude is reduced in botulism and increases after repetitive high frequency nerve stimulation or after exercise.$^{10}$ If, however, as in our case, the CMAP amplitudes are normal, increment is usually not found. Decrement after repetitive nerve stimulation at low frequencies, on the other hand, being borderline in patients 1 and 2 , is also a feature in botulism. ${ }^{9}$

It is well known that local injection of botulinum toxin with therapeutic doses can effect neuromuscular junctions at distant sites. Increased jitter and frequent blockings on single fibre EMG in distant muscles are well documented, ${ }^{3-7}$ and usually interpreted as a sign of presynaptic blockage. Olney et $a l^{3}$ however, found maximal jitter later than 2 weeks after botulinum toxin injections and could never document increased jitter without an increase in fibre density. They regarded these findings as evidence of terminal sprouting rather than presynaptic inhibition.

The patients reported on here show that local botulinum toxin injections can indeed inhibit neuromuscular transmission in distant muscles and cause mild botulism. Denervation in distant muscles on biopsy, shown in patient 1 , has also recently been reported after botulinum toxin injections ${ }^{11}$ and is in keeping with the diagnosis of botulism. Remarkably, although botulinum toxin injections have been used in different countries for many years only two other patients with generalised botulismlike syndrome, similar to our patients have been reported so far. ${ }^{8}$

The pathogenesis of mild botulism in our patients and the patients reported on by Bakheit $e t a l^{\beta}$ is unclear. A particular batch of the toxin cannot be blamed as these patients received toxins from different batches at different times. Hematological spread by inadvertent delivery of the toxin into a blood vessel is unlikely because two of our patients had recurrent episodes consecutively.

The total doses used in our patients were within the range recommended by the British National Formulary for use in torticollis ${ }^{12}$ and were much lower than in earlier reports from the same institution wherein patients were given an average of 1000 mouse units of Dysport for torticollis. ${ }^{1}$ It may be speculated that repeated injections at intervals of $10-12$ weeks as in our patients may have an impact on toxin binding and diffusion. Botulinum toxin binds to specific receptors on nerve terminals and is internalised into the nerve cells. ${ }^{13}$ The receptor binding is irreversible and further binding of the toxin to these sites is therefore blocked. ${ }^{14}$ Functional recovery of poisoned cells is achieved by means of sprouting of new motor nerve axon terminals, which reaches its peak after 5 to 10 weeks. ${ }^{15}$ The status of toxin binding to receptors on these newly sprouted nerve terminals is unclear. It is conceivable that botulinum toxin binding is impaired and 
uptake of botulinum toxin after repeated injections could take place at some distance from the injection site. Diffusion of botulinum toxin within the injected muscle and into adjacent muscles has been well documented ${ }^{16}$ even when these muscles are separated by fasciae. ${ }^{17}$ Diffusion, apart from being dose dependent, ${ }^{17}$ may increase after repeated injection as outlined above and may lead to some degree of systemic spread. Retrograde axonal transport is another possibility. ${ }^{7}$ However, why one of our patients received further botulinum toxin injections at the same interval without the same systemic side effects is difficult to explain.

There has been a case report of systemic effects of local botulinum toxin unmasking subclinical Lambert-Eaton myaesthenic syndrome, ${ }^{18}$ but none of our patients nor the patients reported by Bakheit et al had features suggesting this disease.

It is, however, noteworthy that except for one of our patients with idiopathic cervical dystonia all the other patients (two reported earlier ${ }^{8}$ and two out of our three patients) who had developed generalised weakness after therapeutic doses of botulinum toxin had received their injections either for symptomatic dystonia or (one patient) for spasticity due to multiple sclerosis.

In conclusion, we have described three new patients who developed generalised weakness after focal botulinum toxin injections. The cause is most likely presynaptic inhibition due to systemic spread of the toxin. Which patients have a particular high risk of developing this complication remains to be determined. It is advisable to use botulinum toxin with caution in patients with symptomatic dystonia and other neurological disorders as they may be more prone to develop this complication and to be aware that this can occur sporadically after a therapeutic injection dose in a patient who may have been receiving injections for many years without side effects.
AM is a fellow of the Ernst-Jung Stiftung für Wissenschaft und Forschung in Hamburg, Germany.

1 Anderson TJ, Rivest J, Stell R, et al. Botulinum toxin treatment of spasmodic torticollis. F R Soc Med 1992;85:524-9.

2 Sheean GL, Murray NMF, Marsden CD. Pain and remote weakness in limbs injected with botulinum toxin A for writer's cramp. Lancet 1995;346:154-6.

3 Olney RK, Aminoff M, Gell DJ, et al. Neuromuscular effects distant from site of botulinum neurotoxin injection. Neurology 1988;38:1780-3.

4 Lange DI, Brin MF, Warner CI, et al. Distant effect of local injection of botulinum toxin. Muscle Nerve 1987;10:552-5.

5 Sanders DB, Massey EW, Buckley EG. Botulinum toxin for blepharospasm: single fibre EMG studies. Neurology 1986; 36:545-7.

6 Girlanda P, Guiseppe V, Niclosi C, et al. Botulinum toxin therapy: distant effect on neuromuscular transmission and autonomic nervous system. I Neurol Neurosurg Psychiatry 1992;55:844-5.

7 Garner CG, Straube A, Witt JN, et al. Time course of distant effects of local injections of botulinum toxin. Mov Disord 1993;8:33-7.

8 Bakheit AMO, Ward CD, McLellan DL. Generalised botulism-like syndrome after intramuscular injections of botulinum toxin type A: a report of two cases. 7 Neurol Neurosurg Psychiatry 1997;62:198.

9 Gutman L, Pratt L. Pathophysiologic aspects of human botulism. Arch Neurol 1976;33:175-9.

10 Pickett JB. AAEE case report: botulism. Muscle Nerve 1988; 11:1201-5.

11 Ansved T, Odergren T, Borg K. Muscle fiber atrophy in leg muscles after botulinum toxin type A treatment of cervical dystonia. Neurology 1997;48:1440-66.

12 Joint Formulary Committee. Drugs used in parkinsonism and related disorders. In: British Medical Association, ed. British national formulary. Oxford: The Pharmaceutical Press, 1997;34:225-6.

13 Dolly JO, Black J, Williams RS, et al. Acceptors for botulinum neurotoxin reside on motor nerve terminals and mediate its internalization. Nature 1984;307:457-60.

14 Hambleton P, Moore AP. Botulinum neurotoxin: origin, structure, molecular actions, and antibodies. In: Moore P, ed. Handbook of botulinum toxin treatment. Oxford: Blackwell Science, 1995:16-27.

15 Holland RL, Brown MC. Nerve growth in botulinum toxin poisoned muscles. Neuroscience 1981;6:1167-79.

16 Eleopra R, Tugnoli V, Caniatti L, et al. Botulinum toxin treatment in the facial muscles in humans: evidence of an action in untreated near muscles by peripheral local diffusion. Neurology 1996;46:1158-60.

17 Borodic GE, Ferrante R, Pearce LB, et al. Histologic assessment of dose-related diffiusion and muscle fiber response after therapeutic botulinum A toxin injections. Mov Disord 1994;9:31-9.

18 Erbguth F, Claus D, Engelhardt A, et al. Systemic effect of local botulinum toxin injections unmasks subclinical Lambert-Eaton myaesthenic syndrome. 7 Neurol Neurosurg Psychiatry 1993;56:1235-6. 